\title{
Commentary: Intraoperative lymph node assessment by robotic, video-assisted thoracoscopic surgery, and thoracotomy: None meet the international recommendations

\author{
Diego González-Rivas, MD, FECTS, ${ }^{\text {a,b }}$ and Ramón Rami-Porta, MD ${ }^{\mathrm{c}, \mathrm{d}}$
}

\footnotetext{
From the ${ }^{\mathrm{a}}$ Department of Thoracic Surgery, Shanghai Pulmonary Hospital, Tongji University School of Medicine, Shanghai, China; ${ }^{b}$ Department of Thoracic Surgery and Minimally Invasive Thoracic Surgery Unit, Coruña Hospital, Coruña, Spain; ${ }^{\mathrm{c}}$ Department of Thoracic Surgery, Hospital Universitari Mutua Terrassa, University of Terrassa, Spain; and ${ }^{\mathrm{d}}$ Network of Centers for Biomedical Research in Respiratory Diseases Lung Cancer Group, Terrassa, Spain.

Disclosures: Authors have nothing to disclose with regard to commercial support.

Received for publication June 23, 2019; accepted for publication June 25, 2019; available ahead of print Aug 20, 2019.

Address for reprints: Diego González Rivas, MD, FECTS, Department of Thoracic Surgery, Coruña Hospital, Xubias 84, 15006, Coruña, Spain (E-mail: diego.gonzalez.rivas@sergas.es).

J Thorac Cardiovasc Surg 2019;158:1469-70

$0022-5223 / \$ 36.00$

Copyright (c) 2019 by The American Association for Thoracic Surgery

https://doi.org/10.1016/j.jtcvs.2019.06.088
}

The article by Kneuertz and colleagues ${ }^{1}$ on the comparison of nodal upstaging, number of explored nodal stations, and number of excised lymph nodes in lobectomy by a robotic approach, video-assisted thoracoscopic surgery (VATS), or thoracotomy for clinical (c) N0 and N1 non-small cell lung cancer reveals relevant findings for everyday clinical practice. First, the rate of global nodal upstaging significantly differs among the 3 different approaches, being highest for thoracotomy and lowest for VATS. Second, the rate of N2 upstaging was similar among the 3 approaches. Third, more nodal stations were sampled in the thoracotomy group, although the number of resected lymph nodes was similar in the 3 approaches. These findings indicate that, from the staging point of view, thoracotomy still has some advantage over the endoscopic procedures, because patients undergoing thoracotomy have their tumors better staged; therefore, their prognosis will be more accurate, and postoperative decisions on adjuvant therapy will be more solidly made.

The detail in the number of sampled nodal stations and excised lymph nodes shows that although the total number of excised lymph nodes meets the international recommendations, the total number of nodal stations does not. When systematic nodal dissection was defined in a multidisciplinary and international meeting in $1996,{ }^{2} 2$ standards were accepted: the complete removal of all mediastinal tissue (fat and lymph nodes) of the involved side and the hilar and intrapulmonary nodes or, alternatively, the removal of at least 6 lymph nodes, 3 from 3 mediastinal stations, always including the subcarinal, and 3 from the hilar and intrapulmonary stations. A few years later, when the definitions of complete, incomplete, and uncertain resections were proposed by the International Association for the Study

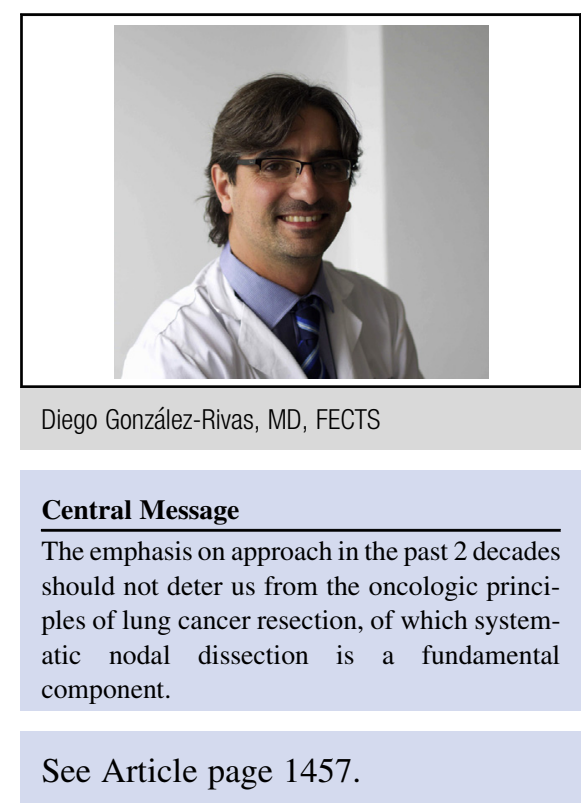

of Lung Cancer, the alternative standard was qualified depending on tumor location, that is, the 3 mediastinal nodal stations to be sampled depended on the lobe of the primary tumor, always including the subcarinal station. ${ }^{3}$ These definitions are not merely the result of a theoretic elaboration. Their prognostic impact has been validated with the International Association for the Study of Lung Cancer database ${ }^{4}$ and with external data. ${ }^{5}$ In the article by Kneuertz and colleagues, ${ }^{1}$ the number of lymph nodes exceeds the minimum of 6 (mean of 11.8, 11.8, and 11.9 for robotic, VATS, and thoracotomy, respectively), but the number of sampled nodal stations do not meet the 6 recommended: 3.8, 3.6, and 4 for robotic, VATS, and thoracotomy, respectively). In addition, in approximately $15 \%$ to $22 \%$ of patients, depending on the approach, the subcarinal nodal station was not sampled. The immediate result of this suboptimal nodal staging is that some tumors do have nodal disease that remains unnoticed, and the prognosis derived from pathologic staging is inaccurate; the late result is that these patients with nodal disease, untreated because it is unknown, will have nodal recurrence, because it is the case even when lobe-specific systematic nodal dissection is performed. ${ }^{6}$

The emphasis on approach in the past 2 decades should not deter us from the oncologic principles of lung cancer 
resection, of which systematic nodal dissection is a fundamental component.

\section{References}

1. Kneuertz PJ, Cheufou DH, D'Souza DM, Mardanzai K, Abdel-Rasoul M, Theegarten D, et al. Propensity-score adjusted comparison of pathologic nodal upstaging by robotic, video-assisted thoracoscopic, and open lobectomy for non'small cell lung cancer. J Thorac Cardiovasc Surg. 2019; 158:1457-66.e2.

2. Goldstraw P. Report on the international workshop on intrathoracic staging, London, October 1996. Lung Cancer. 1997;18:107-11.
3. Rami-Porta R, Wittekind C, Goldstraw P. Complete resection in lung cancer surgery: proposed definitions. Lung Cancer. 2005;49:25-33.

4. Edwards J, Chansky K, Shemanski L, Van Schil P, Asamura H, Rami-Porta R. The IASLC Lung Cancer Staging Project: analysis of resection margin status and proposals for R status descriptors for non-small cell lung cancer. J Thorac Oncol. 2017;12(Suppl 2):s1605.

5. Gagliasso M, Migliaretti G, Ardissone F. Assessing the prognostic impact of the International Association for the Study of Lung Cancer proposed definitions of complete, uncertain, and incomplete resection in non-small cell lung cancer surgery. Lung Cancer. 2017;111:124-30.

6. Maniwa T, Okumura T, Isaka M, Nakagawa K, Ohde Y, Kondo H. Recurrence of mediastinal node cancer after lobe-specific systematic nodal dissection for non-small cell lung cancer. Eur J Cardiothorac Surg. 2013;44:e59-64. 